\title{
UM NATURALISTA E A HISTÓRIA $\left(^{\star}\right)$.
}

\section{PEDRO MOACYR CAMPOS}

Do Departamento de História da Faculdade de Filosofia, Letras e Ciências Humanas da Universidade de São Paulo.

O profundo reflexo exercido na historiografia brasileira pela memória do naturalista alemão Karl Friedrich Philipp von Martius, sob o títu'o Como se deve escrever a história do Brasil, 'confere-lhe uma excepcional posição no panorama cultural do país, até os fins do século XIX, ao menos. Fôra ela ensejada pela decisão do Instituto Histórico e Geográfico Brasileiro, na sua quinta sessão pública aniversária, de propor, para o ano de 1845 , o prêmio de

"uma medalha de ouro, no valor de $200 \$ 000$, a quem apresentar o mais acertado plano de se escrever a história antiga e moderna do Brasil, organizada com tal sistema que nela se compreendam os seus aspectos político, civil, eclesiástico e literário".

Martius, que sempre se mantivera em ligação com o Brasil, desde a viagem que por aqui empreendera (1818-1820), conquistou o prêmio. O correspondente parecer, de autoria de Francisco Freire Alemão, era bem claro quanto aos méritos do trabalho, como se vê:

"se alguma coisa se pudesse dizer contra êle, é que uma história escrita segundo o que aí se prescreve talvez seja inexequífvel na atualidade; o que vem a dizer que êle é bom demais. Porém, não se trata aqui de uma questão de tempo; aí está o modêlo, para quando a coisa fôr realizável".

Quando, algum tempo depois, Varnhagen lançou-se à composição de sua História Geral do Brasil, inspirou-se em Martius; de uma

(*). - O presente trabalho é a reprodução de dois artigos publicados no Suplemento Literário do jornal $O$ Estado de São Paulo nos dias 2 e 9 de abril de 1960. "Republicamo-los para atender a estudantes freqüentemente interessados no assunto. 
ou outra forma, o mesmo fizeram outros historiadores, possìvelmente o próprio Capistrano de Abreu. Ora, justamente contra o respeito em que era tida a memória em questão ergueu-se o temperamento polemista de Sílvio Romero; a seu ver, nada de original haveria nas idéias de Martius, pois

$$
\begin{aligned}
& \text { "um estrangeiro, que nos visitou às carreiras, preocupado com } \\
& \text { coisas de botânica e, no mais, nos desconhecia quase completamente", }
\end{aligned}
$$

apenas teria alinhavado um tecido de lugares comuns acêrca da história do Brasil.

Quer-nos parecer, aqui, que o notável crítico foi um tanto apressado, tomando como evidentes, já no tempo de Martius, uns tantos princípios que, no tempo dêle, Romero, eram realmente indiscutíveis. E' o que se dá, por exemp'o, com o exame da participação das três raças, branca, negra e vermelha, como indispensável para a compreensão da história do País. Certamente, no último quartel do século XIX, tal afirmativa era uma banalidade. Se-lo-ia, entretanto, em 1843, (data da composição do trabalho), quando o negro era escravo, quando tanto tempo ainda faltava para a extinção do cativeiro, dificilmente podendo conceber-se sua consideração no mesmo pé que o elemento branco?

- "Sei muito bem", diz-nos o próprio naturalista, "que brancos haverá, que a uma tal ou qual concorrência destas raças inferiores taxem de menoscabo à sua prosápia; mas também estou certo que êles não serão encontrados onde se elevam vozes para uma historiografia filosófica do Brasil. Os espíritos mais esclarecidos e mais profundos, pelo contrário, acharão na investigação da parte que tiveram, e ainda têm, as raças índia e etiópica no desenvolvimento histórico do povo brasileiro, um nôvo estímulo para o historiador humano e profundo".

Relativamente ao índio, pequena seria a dificuldade, numa época de p.ena idealização do selvagem. Mas o negro, escravo, como elemento constituinte do povo brasileiro? - Seria isto um lugar comum, uma evidência, na primeira metade do século XIX?

Não pretendemos afirmar, com isto, uma real origina lidade de parte de Martius. Bem ao contrário, não acreditamos nesta originalidade e achamos rica em conclusões uma pesquisa orientada para a busca das fontes de sua inspiração. Conseguiremos, através dela, na verdade, um importantíssimo elo de filiação da historiografia brasileira de quase todo o século XIX ao movimento intelectual europeu, dado o fato de se ter atribuido um papel de diretriz à memória do naturalista. 
Uma possibilidade digna de consideração surge ao compararmos as idéias mestras de Martius com as do expoente da escola romântica francesa, que foi Augustin Thierry (1795-1856). Mais do que ninguém, Thierry afirmara a importância do encontro de raças na história de um país. Na introdução à sua Histoire de la conquête de l'Angleterre par les normands, publicada em 1825, referia-se êle à "espada da conquista", que renovou a face da Europa e a distribuição de seus habitantes, deixando sua marca em cada nação, "criada pela mistura de diversas raças". E tôda a história da Grã-Bretanha, nos séculos seguintes à invasão de Guilherme-o-Conquistador, encarava-se, assim, sob o ponto de vista das relações entre as raças postas em contacto, até constituir-se "uma só nação, uma língua comum, uma legislação uniforme". Ora, o caso brasileiro prestava-se às maravilhas para a aplicação de semelhante esquema, e Martius, certamente, conhecia a obra de Thierry. No seu próprio ensaio, aliás, uma passagem pode ser invocada, denunciando a fonte em que abeberava. Ei-la:

\footnotetext{
"Tanto a história dos povos quanto a dos indivíduos nos mostram que o gênio da história (do mundo), que conduz o gênero humano por caminhos cuja sabedoria sempre devemos reconhecer, não poucas vêzes lança mão de cruzar as raças para alcançar os mais sublimes fins na ordem do mundo. Quem poderá negar que a nação inglêsa deve sua energia, sua firmeza e perseverança a esta mescla de povos céltico, dinamarquês, romano, anglo-saxão e normando!"
}

Mais ainda. O cotêjo com a introdução à mencionada obra de Thierry revela-nos ter Martius encontrado realmente uma semelhança entre o processo formativo da Inglaterra, tal como lá se apresentava, e o caso brasileiro. A simples existência de uma raça em situação servil prestava-se a isto, pois seu papel é importantíssimo na visão do processo histórico, segundo o romantismo francês, como se vê:

"As classes superiores e inferiores, que hoje se observam com desconfiança ou lutam unidas em prol de sistemas de idéias e de govêrno, outras não são, em diversos países, além de povos conquistadores e de populaçōes submetidas à servidão de uma época anterior".

Grande diferença não apresentam as palavras do naturalista:

"O sangue português, em um poderoso rio, deverá absorver os pequenos confluentes das raças índia e etiópica. Na classe baixa tem lugar esta mescla, e como em todos os países se formam as classes superiores dos elementos das inferiores, e por meio dela se vivificam e fortalecem, assim se prepara atualmente, na última classe da população brasileira, esta mescla de raças, que daí a séculos influirá pode- 
rosamente sôbre as classes elevadas e lhes comunicará aquela atividade histórica para a qual o Império do Brasil é chamado".

Lembremos, para deixar mais claro o paralelo, a expressa referência de Thierry ao paulatino recrutamento procedido pela raça dominante nas fileiras das camadas inferiores. na "massa laboriosa e pacífica". A semelhança é tão freqüente, de parágrafo a parágrafo, que acabamos por ter a impressão de que, ao compor sua memória, Martius tinha sob os olhos a obra de Thierry. Ainda no concernente à questão de raças, ju'ga êle conveniente insistir na inelutável necessidade de superação de qualquer preconceito, em nome de um procedimento filosófico frente à história. Tal modo de expressar-se, amplamente usado na época, é verdade, encontra-se também na mencionada Introdução de Thierry. Não nos aventuraríamos a buscar aí um nôvo ponto de apôio para nossa hipótese, se o historiador francês o houvesse empregado justamente em conexão com o próprio aspecto do preconceito racial, como se vê:

"Corresponde a falsear a história introduzir-se no seu estudo um desprêzo filosófico por tudo quanto se distancie da uniformidade da civilização atual, e encarar como dignos de consideração apenas os povos a cujo nome $o$ acaso dos acontecimentos liga a idéia e o destino desta civilização" -

- Palavras dêste teor caberiam com uma luva no trabalho de Martius sôbre a história brasileira.

Sílvio Romero, assim, sempre às vo'tas com o panorama cultural europeu, teria achado em Thierry base bem mais plausível, para contestar a originalidade de Martius, do que entre autores quinhentistas, tais fôssem Gabriel Soares de Sousa e Fernão Cardim. Tanto mais quanto as semelhanças entre os dois autores estão longe de limitar-se à questão de raças, como passamos a vêr.

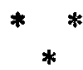

Augustin Thierry, com sua visão da história caracterizada pelo encontro e pelas relações entre as raças, parece-nos ter desempenhado o principal papel, como fonte inspiradora de Martius, relativamente à história do Brasil. Recordemos ainda, em apôio de nosso ponto de vista, que a primeira parte do trabalho do naturalista, dedicado às idéias gerais orientadoras de sua dissertação, trata exclusivamente da questão das raças. Pelo seu exame, portanto, pautar-se-ia a elaboração da história brasileira, uma vez que - segundo o próprio Martius - 


\begin{abstract}
"a cada uma das raças humanas compete, segundo sua fndole inata, segundo as circunstâncias debaixo das quais ela vive e se desenvolve, um movimento histórico característico e particular".
\end{abstract}

Outros pontos, todavia, não lembram apenas Thierry, mas tôda a escola dos historiadores liberais franceses. Se nos voltarmos para os traços marcantes desta fase da historiografia, encontraremos, logo de início, seu caráter pragmático: Os movimentos liberais e nacionais proporcionavam o ambiente para o seu desenvolvimento, consistindo um de seus objetivos, por outro lado, em buscar no passado argumentos a favor da liberdade, contra os regimes de opressão. Em matéria política, naturalmente, defendiam a monarquia constitucional, com especial simpatia pelo modêlo inglês. Anti-aristocrática, portanto, era sua orientação; sua afinidade era com as lutas e ideais da burguesia, incluindo-se em seu programa a defesa das populações oprimidas. $\mathrm{Na}$ obra de Thierry destacam-se frisantes exemplos destas tendências, mas o mesmo verifica-se com Guizot, Thiers ou Mignet. Partindo desta linha principal, os historiadores liberais não limitam o campo da história a uma classe, ou a um setor especial de atividades, procurando, ao contrário, abranger o conjunto da atividade humana, em tôdas as camadas sociais. A tal respeito, aliás, Voltaire é geralmente tido como um de seus precursores.

Ora, chega a surpreender-nos a maneira pela qual todos êstes itens são adotados por Martius e recomendados para se aplicarem ao caso brasileiro. O simples fato de se encararem as raças em pé de igualdade, perante a história, já denuncia uma orientação liberal. Mas muito mais claramente podemos afirmá-la, lembrando o seguinte parágrafo, concernente aos negros e índios:

'Com quanto mais calor e viveza êle ( o historiador) defender em seus escritos os interêsses dessas por tantos modos desamparadas raças, tanto maior será o mérito que imprimirá à sua obra, a qual terá igualmente o cunho daquela filantropia nobre, que em nosso século com justiça se exige do historiador. Um historiador que mostra desconfiar da perfectibilidade de uma parte do gênero humano, autoriza o leitor a desconfiar que êle não sabe colocar-se acima das vistas parciais ou odiosas".

O pragmatismo da história é, também, expressamente invocado, tomando-se, ainda, a monarquia constitucional como uma verdadeira necessidade, especialmente para o Brasil.

\footnotetext{
"Nunca esqueça, pois, o historiador do Brasil, que para prestar um verdadeiro serviço à sua pátria, deverá escrever como autor monárquico-constitucional",
} 
lemos nas recomendações finais. O historiador, sempre supondo-se ser êle um patriota, deveria agir como um colaborador da união nacional, cabendo-lhe

"aproveitar tôda e qualquer ocasião para mostrar que tôdas as providências do Império, por lei orgânica, se pertencem mùtuamente, que seu próprio adiantamento só pode ser garantido pela mais intensa uniāo entre elas".

O princípio das nacionalidades, assim, tem aqui o seu lugar. Note-se, ainda neste tocante, a diferença entre o pensamento de Martius e o que se manifesta nos discursos pronunciados nos primeiros tempos do Instituto Histórico e Geográfico Brasileiro. Ambos os lados referem-se à exigência do pragmatismo do historiador. Mas enquanto que os brasileiros insistem no significado da história como uma galeria de exemplos de virtudes individuais, de valores pessoais, à maneira de Plutarco, já o alemão não faz qualquer referência ao papel das grandes personalidades do passado como modelos de procedimento. Para êle, o importante é o conjunto da população, a merecer tôdas as atenções do historiador. Este deve

\footnotetext{
"transportar-nos à casa do colono e cidadão brasileiro; êle deve mostrar-nos como viviam, nos diversos séculos, tanto nas cidades como nos estabelecimentos rurais, como se formavam as relações do cidadão para com seus vizinhos, seus criados e escravos; e finalmente, com os fregueses nas transações comerciais, êle deve juntar-nos o estado da Igreja, a escola, levar-nos para o campo, às fazendas, roças, plantações e engenhos".
}

A vida científica, moral e social dos habitantes do Brasil inicia-se no seu campo de cogitações, conduzindo-nos sempre a uma concepção orientada para o povo, na sua totalidade. Vêm-nos à memória Michelet, com a ressurreição da vida integral do passado, e Thierry, novamente. Certas passagens dêste último parecem aqui ter servido de base, a começar pela seguinte confissão:

"Sem dar aos grandes fatos da história atenção menor do que merecem, interessei-me com afeição tôda especial pelos acontecimentos locais, relativos às populações negligenciadas" (Histoire de la Conquête de l'Angleterre, Introdução).

Por outro lado, distingüir-se-ão semelhanças, até mesmo de ordem formal, se cotejarmos a passagem de Martius que por último transcrevemos com o prefácio aos Récits des temps mérovingiens, também de A. Thierry. E, na primeira das Lettres sur l'histoire de France, há algo que confirma, ainda uma vez, o parentesco entre as recomen- 
dações do naturalista e os princípios dos historiadores liberais, como se vê:

"A verdadeira história de uma nação, a história realmente digna de tornar-se popular, jaz ainda enterrada na poeira das crônicas. Ninguém foi lá buscá-la; e as inexatas, falsas e descoloridas compilações que, na falta de melhor palavra, honramos com o nome de "histórias da França" continuam a ser. impressas. Naquelas vagas e pomposas narrativas, nas quais umas tantas personagens privilegiadas monopolizam o palco. histórico, enquanto a massa da totalidade da nação esconde-se por trás dos mantos dos cortesãos, em parte alguma entramos instrução séria, ou lições aplicáveis a nós mesmos, ou aquela simpatia que, em geral, associa os homens ao destino daqueles que se lhes assemelham".

Outra das observações de Martius, dentre as mais famosas, concerne ao agrupamento das províncias brasi.eiras pelo historiador, de modo a serem

'tratados conjuntamente aquelas porções do país que, por analogia de sua natureza física, pertençam, umas as outras. Assim por exemplo, converge a história das províncias de São Paulo, Minas, Goiás e Mato Grosso; Maranhão liga-se à do Pará" etc. .

O contacto direto do historiador com as diferentes regiôes exigia-se como indispensável para a avaliação e explicação dos acontecimentos, através da

"particularidade do solo que o homem habita. Quão diferente é o Pará de Minas! Uma outra natureza, outros homens, outras precisōes e paixões e, por conseguinte, outras conjunturas históricas".

Permanecemos na órbita dos liberais franceses. Michelet, agora, proporciona-nos o paralelo, com seu Tableau de la France, publicado em 1835, no $2^{\circ}$ vol. de sua Histoire de France. O legítimo ponto de partida da história, para êle, estaria no quadro geográfico, encarando-se o país segundo suas divisões físicas e naturais. Antes de tudo, a história é geografia, e a consideração das províncias francesas, com base em suas características naturais, explicaria o seu desenvo.vimento histórico. Onde, melhor do que aí, poderia Martius buscar seu modêlo, neste aspecto de suas considerações?

Tudo isto é tanto mais interessante, quanto muito pouco notamos que denote algum reflexo da historiografia prussiana, marcada pela erudição, pela crítica das fontes, na disertação de Martius. Ora, já em 1824 Ranke publicara o primeiro volume de sua inacabada História 
dos povos românicos e germânicos, com o memorável apêndice relativo ao estudo crítico dos documentos utilizados. Em Martius, é verdade, há uma ou outra referência à necessidade da busca de fontes. Mas suas idéias, concernentes à forma que deveria ter uma História do Brasil, são decisivas e nos põem muito mais ao lado dos franceses do que da escola prussiana. Assim é que a

"a obra deverá ser escrita em um estilo popular, posto que nobre. Deverá satisfazer não menos ao coração do que à inteligência; por isso não deverá ser escrita em linguagem empolada, nem sobrecarregada de erudição ou de uma multidão de citações estéreis. Evitará não menos ter o caráter de uma crônica, do que de investigações históticas secas e puramente eruditas".

Palavras como estas seriam perfeitamente cabíveis a um Augustin Thierry. $O$ alemão Martius, enfim - a termos razão em nosso hipótese - teria sido um importante veículo da influência francesa no desenvolvimento cultural brasileiro. Tantos e tão diversos são os caminhos da História... 